E3S Web of Conferences 1, 32010 (2013)

DOI: $10.1051 / \mathrm{e} 3 \operatorname{sconf} / 20130132010$

(C) Owned by the authors, published by EDP Sciences, 2013

\title{
Evaluation of anthropic influences in an estuarine system of Southeastern Brazilian Coast by applying enrichment factors
}

\author{
C. Goncalves ${ }^{1}$, R. C. L. Figueira ${ }^{2}$, J. R. Sartoretto ${ }^{2}$, A. B. Salaroli ${ }^{2}$, B. S. M. Kim ${ }^{2}$ and M. M. Mahiques ${ }^{2}$ \\ ${ }^{1}$ Consultoria, Planejamento e Estudos Ambientais - CPEA, Sao Paulo/SP, Brazil \\ ${ }^{2}$ Oceanographic Institute of Sao Paulo University - Sao Paulo/SP - Brazil
}

\begin{abstract}
This study presents an evaluation of metals and As deposition in the Bertioga Channel (Santos Region, Southeastern Brazilian coast) along the last 150 years, which corresponds to the main anthropogenic activity in the area. The studied area is located in the so-called Baixada Santista, where the main Brazilian harbor and one of the most important industrial centers of the country are located. This work consisted of sampling five sediment cores along this channel. The cores were sliced every $2 \mathrm{~cm}$, and the samples were analyzed by ICP-OES to determine the levels of heavy metals $(\mathrm{Cd}, \mathrm{Cr}, \mathrm{Cu}, \mathrm{Ni}, \mathrm{Pb}$ and $\mathrm{Zn})$ and $\mathrm{As}$. The enrichment factors (EF) were calculated to identify the relative heavy-metal toxicity of the sediments and the anthropogenic contribution of the investigated elements. EFs indicated the absence of contamination for the heavy metals but a higher input of As in two cores (B2 and B5). According to the age models of the cores, this enrichment corresponds to the end of the $19^{\text {th }}$ century, when Santos harbor was inaugurated, and to the 1970s, when Santos harbor activities expanded.
\end{abstract}

Keywords: pollution load index, enrichment factor, heavy metal, marine sedimentas, Brazilian coast, estuaries

\section{Introduction}

Santos estuary, located in Southeastern Brazilian Coast, is impacted by several anthropic activities. The largest commercial harbor in South America and the main petrochemical and metallurgical industrial centre in the country, with approximately 1100 industries, are also in this estuary(CETESB, 2001). The estuarine system has an important channel, called Bertioga Channel, which connects the upper Santos estuary with the ocean. In this channel are located the main mangroves of the estuarine complex that has a great potential of heavy metals retention. This behavior is related to sedimentary dynamics of system, where contaminated sediments from upper estuary are filtrated by channel before reaching the ocean.

In this context, the main goal of this work was to carry out a study on toxic elements in cores from Bertioga Channel. Enrichment Factor (EF) was determined and it was related to geochronological data, allowing the evaluation of anthropic activities impact in this region. Thus, in February 2010, were collected five cores along the channel (Figure 1), using a vibrocorer. The cores $(150-220 \mathrm{~cm})$ were sliced at every $2 \mathrm{~cm}$, the samples were frozen and freeze-drying.
Elemental preparation and analysis $(\mathrm{As}, \mathrm{Cd}, \mathrm{Cr}, \mathrm{Cu}, \mathrm{Ni}$, $\mathrm{Pb}, \mathrm{Sc}$ and $\mathrm{Zn}$ ) followed $\mathrm{SW}-846$ methodologies (USEPA, 1996, 2007), applying ICP-OES technique (Varian MPX 710ES model). Geocronology was determined via gamma spectrometry, by ${ }^{210} \mathrm{~Pb}_{\mathrm{xs}}$ and ${ }^{137} \mathrm{Cs}$ methods, using a low background Ge detector, EG\&G Ortec, model GMX 25190P, as described by Figueira et al. (2007).

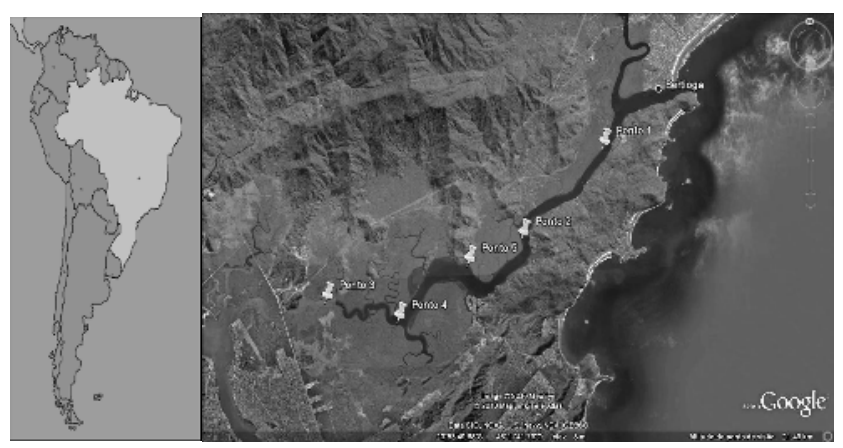

Fig. 1. Sampling cores along Bertioga Channel (Southeastern Brazilian Coast). 
a)

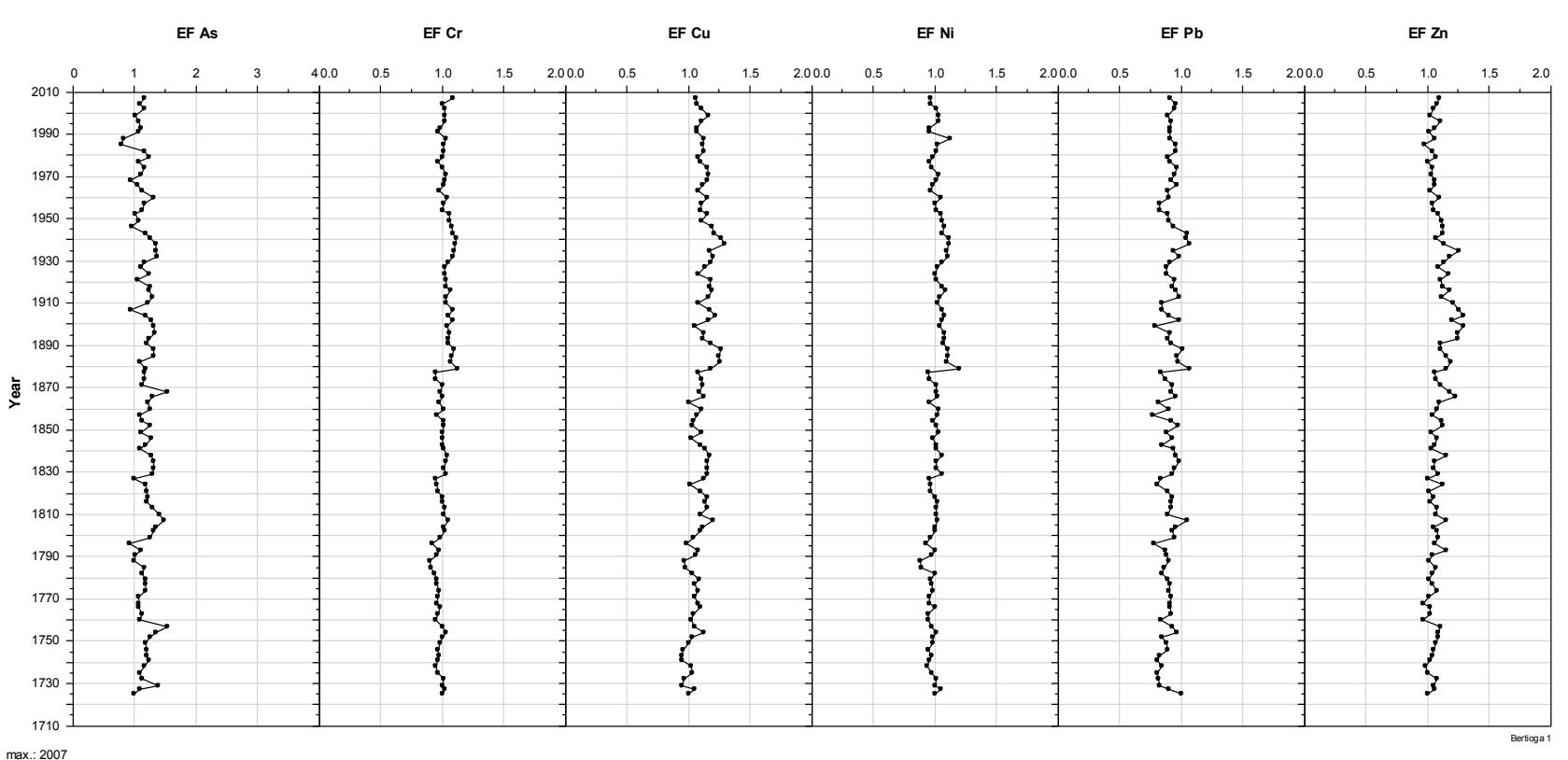

b)

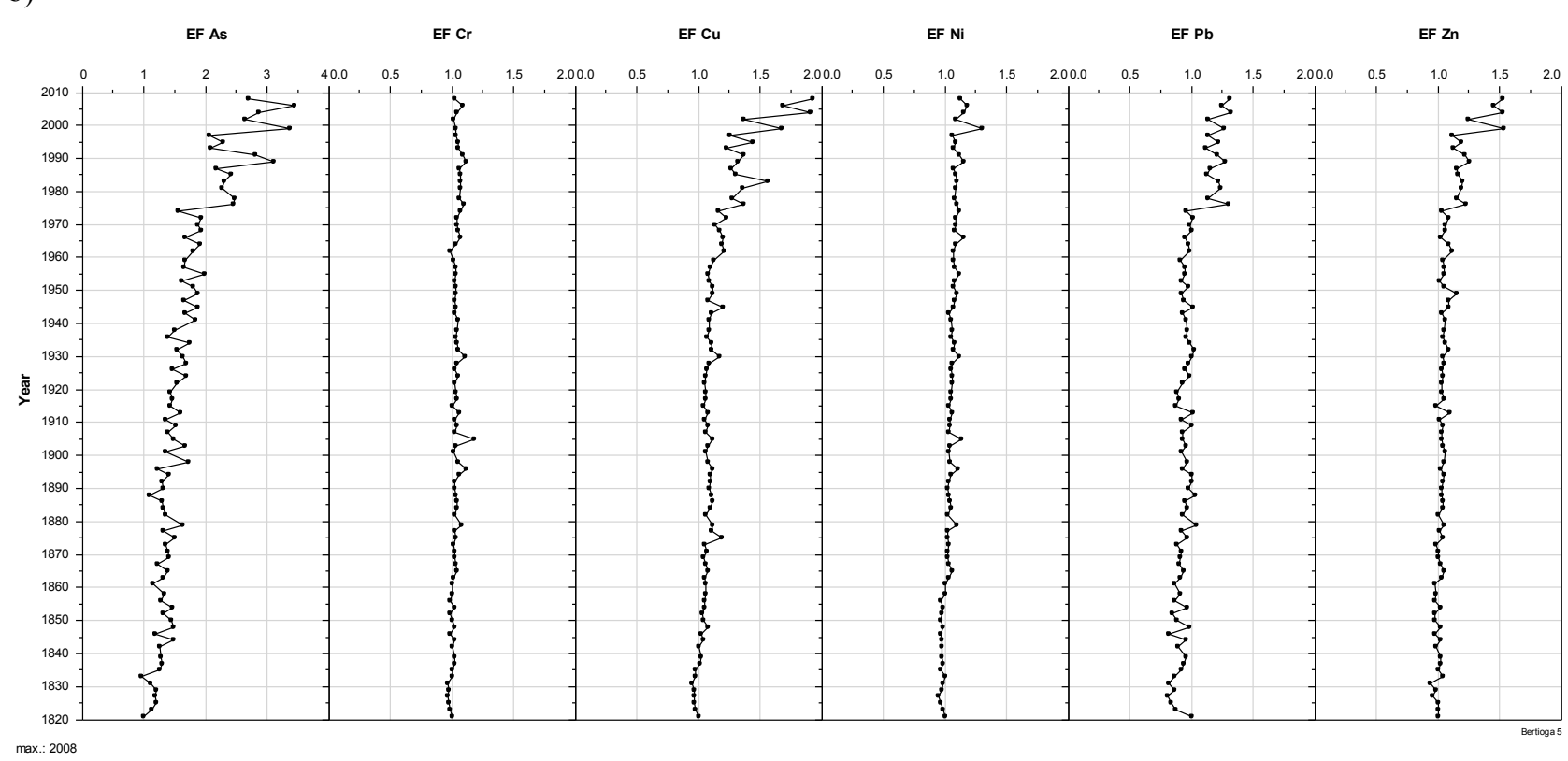

Fig. 2. Enrichment factor in two cores from Bertioga Channell. (a) Bertioga 1 and (b) Bertioga 5

In order to assess the degree of sediment contamination, enrichment factors (EF) were calculated using Sc as normalization element, according to the formula:

$$
\mathrm{EF}=\left([\mathrm{Me}]_{\mathrm{i}} / \mathrm{Sc}_{\mathrm{i}}\right) /\left([\mathrm{Me}]_{0} / \mathrm{Sc}_{0}\right)
$$

$X_{i}$ - metal concentration value in the sample; $X_{0}$ - metal background value; $S c_{i}$ - Sc concentration in the sample; $S c_{0}$ - Sc background value.
Background values corresponded to the element concentration in the bottom sediment core as determinedby ${ }^{210} \mathrm{~Pb}$ chronology. The five-category pollution index (Andrews \&; Sutherland, 2004) was used for the pollution assessment: $\mathrm{EF}<2$, minimal pollution; EF 2-5, moderate pollution; EF 5-20, significant pollution; EF 20-40, high pollution; and EF $>40$, extreme pollution. Figure 2 presents Enrichment Factor in two of the five cores collected along Bertioga channel. Figure 2a 
corresponds to the core with the lowest EF and Figure $2 \mathrm{~b}$ corresponds to the core with the highest calculated EF.

EFs obtained in all analyzed cores were lower than 2, indicating a minimal pollution for the region. However, in core Bertioga 5 (the closest one to Santos harbor), it can be seen $\mathrm{As}, \mathrm{Cr}, \mathrm{Pb}$ and $\mathrm{Zn}$ enrichment from the bottom to the top, mainly from 70's, when harbor activities expanded. Despite of the low levels found for the studied elements, Bertioga channel area has suffered environmental impact due to domestic sewer releasing and the presence of marina in the region.

\section{References}

Andrews, S.; Sutherland, R. A. 2004. Cu, Pb and Zn contamination in Nuuanu watershed, Oahu, Hawaii. Sci. total Environment, v. 324, p. 173-182.
CETESB, 2001. Relatório do Sistema Estuarino Santos e São Vicente.

$<$ http://www.cetesb.sp.gov.br/agua/praias/25publicacoes-/-relatorios $>$

Figueira, R.C.L.; Tessler, M.G.; Mahiques, M.M.; Fukumoto, M.M. 2007. Is there a technique for the determination of sedimentation rates based on calcium carbonate content? A comparative study on the Southeastern Brazilian shelf. Soils and Foundations, 47: 649-656.

US EPA, 1996. Method 3050B - Acid Digestion of Sediments, Sludges, and Soils, revision 2, 12 p.

US EPA, 2007. Method 6010C - Inductively Coupled Plasma-Atomic Emission Spectrometry, revision 3, $34 \mathrm{p}$. 